\title{
NOUVELLE CONTRIBUTION A L'ÉTYMOLOGIE DU TOPONYME LJUBLJANA
}

Ce n'est sans doute pas un hasard si les toponymes Ljubljana, Lubiana et Laibach se sont vu attribuer une série d'explications étymologiques et ceci par d'éminents linguistes slovènes tels que Miklošič (1859), Kelemina (1950), Ramovš (1953), Bezlaj (1956) auxquels on ajoutera également le grand croate Petar Skok (1934) et surtout à la fin des années soixante-dix, Anton Grad, professeur titulaire à la chaire de français de l'Université de Ljubljana $(1978,1980)$.

Pour ce qui concerne Ljubljana les slavisants auraient choisi une racine anthropomorphique slave $L$ 'ub à laquelle s'ajouteraient des suffixes éthniques du type -jan-ine au pluriel ; Kelemina a préféré le choix d'une base adjectivale l'ub suivie des suffixes -ja-na. Notons cependant que Bezlaj reste inexplicablement indécis et qu'il laisse ouvertes toutes hypothèses possibles et imaginables, entre autres une origine préslave de 1'hydronyme initial Ljubija.

Quant à Grad, il bâtit son explication sur une origine romane (ô combien acceptable de nos jours et combien mal vue, il y a un bon quart de siècle !) - *alluviana, forme elliptique de (aqua) *alluviana »eau qui déborde, inonde, submerge le terrain riverain, y dépose de la boue etc., crée des marais, ce qui, en effet, a toujours été (et est encore) un trait caractéristique de la rivière en question«. Ces interprétations sémantiques nous semblent effectivement fort acceptables. Il est évident, cependant, que les développements phonétiques vers les formes Lubiana, Ljubljana et Laibach ont pu paraître, à l'époque, quelque peu simplificateurs, pourtant le fait qu'il n'y ait pas eu d'oppo sition définitive, laisse l'espoir qu'elles peuvent parâtre plausibles encore aujourd'hui, bien que parfois non très ortodoxes.

Mis à part le respect que nous devons à notre éminent prédecesseur à la chaire, mais peut-être mus par le désir de renouveler le défi en matière diachrono-socio-linguistique, plus particulièrement à l'occasion de ce volume de Linguistica que son méritant rédacteur en chef, Mitja Skubic, offre en hommage à l'académicien Janez Orešnik (lequel aurait fourni des données enrichissantes au dernier »interprête « du toponyme de Ljubljana), nous proposons deux solutions possibles et de par ce fait critiquables :

- 1) *luppa: étymon celtique signifiant» argile, terre grasse, glaise « ou encore préceltique *lappa, signifiant $»$ schlamm $\ll+\mathrm{i}$-ana (suffixe hydronimique latin): Wartburg, FEW, V, J-L(p.457)

- $\quad$ 2) *lupia (luoghi sabbionosi ed incolti; campi dove il fiume si spande (onde 
il verbo lubia 'scoscendere') + -ana (suffixe hydronymique latin): D. Olivieri: Toponomastica Veneta (p.105)

Nous avons une petite préférence pour la première proposition: elle réconcilie les deux variantes ultérieures: la latino-slave Lubiana-Lubljana et la germanique Laibach selon les gradations phonétiques proposés par A. Grad(1980), et correspond à la fois aux exigences sémantiques et logistiques de la sociolinguistique moderne. Notons que le toponyme d'une grande métropole culturelle européenne Louvain s'alignera peutêtre un jour, si ce n'est pas très prochainement, dans ce contexte précis, à celui de la capitale slovène. Et pourquoi pas le Louvre - grève inondée? Et le village slovène de Ljubno dans la valée de la Savinja, ayant depuis son existence, des problèmes avec l'eau »roide« qui l'inonde?

Il nous faut avouer cependant que, voulant rester fidèles aux pistes romanes parcourues par le professeur Grad, nous préconisons aussi l'étymologie »louparde« de notre capitale, bien que contestée par A. Dauzat (et al.: Dict. étym. des noms des rivières...): »les formes mediévales lupa sont de mauvaises latinisations (par attraction de lupus, loup); des rivières dormantes ne peuvent avoir reçu le loup pour emblème et le $-p$ - serait devenu $-v$-; il s'agit d'une rac. hydron. low-, sans doute préceltique, cf. irlandais $l o$, eau (p.61).«

Dans un contexte plus léger, culturel cependant, il faudrait citer les voisins européens: Louviers, Louveciennes, La Louvière. Et pourquoi ne pas leur associer Luwigana (?), ancienne appelation de Ljubljana, Ljubno en Haute-Carniole (loin de toute eau inondatrice), et Ljubelj, col de montagne se prêtant parfaitement à la denture du loup - Lupillum, et rejoignant tant d'exemples sur le territoire de la Gallia »romanica«? Sans parler de Ljubogojna, Ljubečna, Ljubela, Ljubinski potok, Libeliče; Voše, Vovše, Volčji potok, Volčja draga etc.

La confusion est parfaite. La phonétique historique impose ses règles, parfois quelque peu trop rigides... A qui d'instituer l'ordre? Aux scientifiques, bien évidemment. La course au premier prix est ouverte... 


\section{Bibliographie:}

BEZLAJ, F.- Slovenska vodna imena, I., Ljubljana, SAZU, 1956

DAUZAT, A. - La Toponymie française, Paris, Payot 1946

DauZAT, A. et al.- Dictionnaire étymologique des noms de rivières et de montagnes en France, Paris, Ed. Klincksieck, 1978

GrAD, A.- K etimologiji toponima Ljubljana; Onomastica jugoslavica, 7, Zagreb 1978

GRAD, A.- Prispevek k etimologiji toponimov Ljubljana, Lubiana, Laibach; Slavistična revija, 1, Ljubljana, 1980

OLIVIERI, D.- Toponomastica veneta, Istituto per la collaborazione culturale, Venezia-Roma,

Schlamberger M., Pogačnik V., Perko G.- Parlons slovène, Paris, l'Harmattan, 2005

WARTBURG, W. von.- Französisches Etymologisches Wörterbuch, V., Basel.Helbing\&Lichtenhahn, 1950

\section{Povzetek}

\section{NOV PRISPEVEK K ETIMOLOGIJI TOPONIMA LJUBLJANA}

Prispevek k obnovljenemu razmišljanju o etimologiji toponima Ljubljana nakazuje več možnih, a vsekakor neslovanskih oz. neslovenističnih rešitev: keltski etimon luppa, predkeltski lappa (oba: blato, močvirje, morost)- slednji se bo verjetno bolje prilegal germanskemu postreliktu Laibach - ter romanski lupia »volčji vrelec, ponikovalne narave«, hidronimi, ki se zdijo naravnejši in zlasti manj moteče »tehnični« od Gradove »alluviane«, poplavne reke, in ki se več ali manj vsi kar dobro prekrivajo s prvim vrelcem Ljubljanice, Ljubijo. Kar zadeva vodotočno pripono -ana in vse različne fonetične spekulacije, se avtor ne spušča v polemiko s prof. Gradom niti z njegovimi morebitnimi oponenti, misleč skromno, da ni nič bolj fonetično od nefonetičnega, seveda $\mathrm{v}$ strukturiranem jezikovnem kontekstu. 